\title{
Usos de expresiones condicionales en diálogos argumentativos entre adultos mayores chilenos ${ }^{1}$
}

\section{The uses of conditional expressions in argumentative dialogues between chilean elderly people}

\author{
CRISTIÁN SANTIBÁÑEZ \\ JUAN CORTÉS \\ ${ }^{a}$ Universidad Católica de la Santísima de Concepción, Facultad de Educación. Chile. \\ Correo electrónico: csantibanez@ucsc.cl \\ ${ }^{b}$ Universidad de Talca, Facultad de Humanidades, Chile. \\ Correo electrónico: jcortes@utalca.cl
}

\begin{abstract}
Qué tipos de estructuras condicionales expresan los adultos mayores cuando discuten contenidos dilemáticos, es la pregunta de investigación que motivó este trabajo. Para responder la pregunta se discute primero la importancia del pensamiento condicional e hipotético; luego el trabajo sigue con el análisis de diálogos argumentativos de adultos mayores en diadas y triadas en términos de las premisas fuerza de las estructuras condicionales, la frecuencia de estructuras condicionales según las variables género, educación, edad y ubicación geográfica en Chile, y una evaluación de los usos taxonómicos de los condicionales encontrados en sus opiniones. Entre los hallazgos destaca que una gran cantidad de condicionales son consejos, que otro porcentaje importante fueron condicionales contrafactuales y deónticos, caracterizándose estos últimos como condicionales prácticos que dan instrucciones en un esquema evento-acción. Los hallazgos más importantes, no obstante, son que las premisas fuerza tienen un rol clave en los enunciados condicionales de los adultos mayores, y que la variable que genera una diferencia cuando se comparan las diadas y triadas es ubicación geográfica, y no así educación, género o tramo etario específico dentro de la adultez mayor.
\end{abstract}

Palabras claves: adultos mayores, argumentación, pensamiento condicional, dilemas sociales.

What types of conditional structures do older adults express when they discuss dilemmatic contents, is the research question that motivated this work. To answer this question the importance of conditional and hypothetical thinking is first discussed; then we continue with the analysis of argumentative dialogues between elderly people in dyads and triads in terms of the driven premises of conditional structures, the frequency of conditional structures according to variables such as gender, education,

\footnotetext{
${ }^{1}$ Este trabajo es parte del proyecto Fondecyt Regular 1170492.
} 
age and geographical location in Chile, and an evaluation of the taxonomic uses of the conditionals found in their opinions. Among the findings it stands out that a large number of conditionals are advice, that another important percentage issued were counterfactual and deontic conditionals, the latter being characterized as practical conditionals that give instructions in an event-action scheme. The most important findings, however, are that the driven premises play a key role in the conditional statements of elderly people, and that the variable that generates a difference when comparing dyads and triads is geographic location, and not education, gender, or specific age interval within elderly.

Key words: elderly people, argumentation, conditional thinking, social dilemmas.

\section{INTRODUCCIÓN}

El pensamiento y el discurso condicional es de gran importancia tanto para la estructuración psíquico-cognitiva como para la vida conjunta entre las personas. Pareciera ser que esto es así porque el procedimiento cerebral más básico produciría representaciones hipotéticas rápidas antes de generar decisiones. Como lo ha propuesto Lawson (2004), el contenedor cerebro-mente no funcionaría de manera inductivamente numerativa o agregacionista, sino de una forma predictivo-hipotética utilizando la estructura condicional Silentonces/luego. Según este autor, se ha observado que es sólo desde los 8 años que los infantes utilizan esta forma, ya que antes en ellos domina el sesgo de perseverancia, es decir, la incapacidad de cambiar de una regla a otra de razonamiento cuando el problema lo requería, como por ejemplo pasar de una regla deductiva a una abductiva, necesitando esta última algún elemento condicional. Para Lawson (2004: 17) el cerebro funcionaría siguiendo una ruta como la siguiente: 1) El agente se encuentra frente a una observación que genera un cierto conflicto cognitivo; 2) Emerge una pregunta causal (por ejemplo: ¿por qué pasa la anomalía que observo?); 3) Se generan una o más hipótesis, subproceso en el que intervienen analogías, transferencia analógica, o razonamiento analógico, esto es, patrones de respuesta que han funcionado en el pasado en contextos relacionados o similares; 4) Se asume una hipótesis como correcta para testearla y ver si sus predicciones son verosímiles; 5) Se lleva acabo el test imaginado; 6) Se comparan los resultados imaginados con los resultados observados, esta comparación permite obtener una conclusión; y 7) Se recicla el proceso hasta que una hipótesis con mayor apoyo se genere si el mapeo entre resultados imaginados y observados no es del todo convincente, teniendo en cuenta que mayor apoyo significa mayor respaldo, pero no que haya sido probada tajantemente.

El énfasis de Lawson es que el razonamiento adaptado exitosamente genera en el agente un hábito de inhibición por defecto de hipótesis anteriormente utilizadas sin éxito, al mismo tiempo que elimina información irrelevante. La importancia de la capacidad de producir eventos condicionales y escenarios hipotéticos también radica en que refleja niveles superiores de intencionalidad (Evans 2007 y 2010). En términos de pensamiento 
hipotético, para creer algo necesito solo representaciones, pero para suponer algo requiero meta-representación. El rendimiento cognitivo de esta capacidad es vasto, pues la posibilidad de suponer cosas produce la capacidad estratégica de ponderar escenarios contrafácticos.

Frente a esta importancia del pensamiento condicional e hipotético, cabe preguntarse ¿qué sucede con tal capacidad en los adultos mayores (en adelante AM) cuando la utilizan en diálogos argumentativos? La pregunta es acuciante porque hay dos hechos que la motivan: el decaimiento cognitivo normal de todas nuestras facultades a medida que avanza nuestra edad y, desde el punto de vista social, el crecimiento sistemático de la población adulta mayor en el mundo y en Chile en particular (INE 2018).

Este artículo reporta un análisis discursivo y argumentativo de los eventos condicionales extraídos desde actividades dialógicas en las que los participantes AM reflexionaron en torno a un dilema social. Los objetivos de este trabajo son: 1) Identificar, describir y analizar el uso de eventos condicionales en diálogos diádicos y triádicos; 2) Identificar, describir y analizar secuencias argumentativas en tales diálogos; y 3) Clasificar los eventos condicionales en relación con la taxonomía detallada en el apartado 2.2. y su relación con las premisas fuerza encontradas en los dilemas.

Para alcanzar estos objetivos, se procede como sigue: en la sección 2 correspondiente al marco teórico, entregamos primero (en 2.1.) un resumen de estudios empíricos sobre la facultad argumentativa en AM, y luego (en 2.2.) las distinciones conceptuales que utilizamos para operacionalizar la noción de evento condicional. En la sección 3, entregamos los detalles metodológicos de esta investigación; en la sección 4 presentamos, analizamos y discutimos los hallazgos; y en la discusión y conclusiones enfatizamos los puntos más importantes.

\section{Marco teórico}

\subsection{Manifestación argumentativa en $A M$}

Entre los recientes hallazgos relativos al discurso en AM, se ha podido observar que utilizan estructuras gramaticales más simples con extraños que los jóvenes (Luo, Robbins, Martin y Demiray 2019). Los diálogos con personas desconocidas involucran el uso de nueva información, lo que impone mayores desafíos cognitivos y presiona a los participantes a reducir la complejidad gramatical, siendo el caso que los AM se afectan por esto más que los jóvenes y los adultos jóvenes. Se pudo concluir, preliminarmente, que el uso de palabras únicas y la complejidad gramatical variaban cuando los hablantes interactuaban con distintos tipos de personas (niños, amigos, extrańos, o en conversaciones con varios hablantes diferentes).

Pero ¿qué acontece con la facultad de emitir discurso argumentativo en AM? Se ha podido observar (Santibáńez y Gascón 2020) que, insertos en un diálogo controversial sobre dilemas sociales que contienen algún problema moral, tienden a usar mayoritariamente esquemas argumentativos de fines a medios (a diferencia de adultos jóvenes -de 18 a 25 
años- que tienden a usar esquemas basados en reglas y normas). Se interpretó este hallazgo como una tendencia propia del desarrollo moral entre ambos grupos, según la cual los AM poseen patrones más utilitaristas y los jóvenes se inclinan más hacia el deontologismo en la discusión de problemas éticos (Lange, Rockenbach y Yamagishi 2014).

También se ha constatado (Santibáńez y Gascón 2020) que los porcentajes de argumentos simples y complejos en AM y adultos jóvenes son similares. Los argumentos simples se definieron como aquellos que contenían solo un esquema argumentativo, y los complejos como aquellos que tenían más de un esquema (signo, causal, analógico, etc.). En la dimensión de la calidad de los argumentos de los AM, se pudo apreciar que no existe una diferencia importante respecto de los argumentos entregados por los adultos jóvenes, de modo que la longevidad no parece ser una variable relevante. En el estudio citado, la calidad se midió una vez asignado un esquema argumentativo a un argumento, utilizando una escala de 0 a 5 basada en los criterios de aceptabilidad, pertinencia y suficiencia argumentativa. Las diferencias en calidad argumentativa entre los grupos etarios estuvieron determinadas por variables tales como el género (por ejemplo, mujeres AM más educadas tienden a argumentar mejor que hombres AM más educados), la educación (a mayor nivel educación mayor calidad argumentativa), la edad dentro del grupo de los AM y la residencia en zonas más urbanizadas (personas AM que viven en grandes ciudades tienden a argumentar mejor que personas residentes en lugares menos urbanizados).

A partir de un análisis léxico-métrico de las respuestas escritas de los AM a un dilema social (Santibánez 2019), se observó que la densidad argumentativa (en términos de cantidad y pertinencia de razones esgrimidas) de los que rechazaron realizar una denuncia a la policía -en relación con el contenido del dilema- era claramente más robusta. Se vinculó este hallazgo con el sesgo en la información contenida en el propio dilema (relativa a las bondades del comportamiento del protagonista de la historia del dilema posterior a su paso por la cárcel), lo que entregaba más hechos y permitía generar de forma más segura, epistémicamente hablando, la justificación de un punto de vista.

Desde el punto de vista de la psicología de la personalidad y de la comunicación, algunos estudios (Soto, John, Gosling y Potter 2011), demostraron que las personas sobre 65 años son más auto-disciplinadas, más altruistas, pero menos asertivas que los más jóvenes; la tendencia neurótica, psicológicamente considerada, declina con el paso de los ańos. En lo relativo al vínculo entre envejecimiento y agresividad, Schullery y Schullery (2003) pudieron concluir que la agresividad comunicativa decae en las personas con el paso del tiempo, y que la argumentatividad, definida de forma general como la inclinación a involucrarse en desafiar y defender puntos de vista, también decae con los años. En un estudio con población norteamericana (Birditt y Fingerman 2005), se entrevistó a 200 personas cuyas edades fluctuaban entre los 18 y 99 años, y se concluyó que los adolescentes eran más proclives a exhibir conflictos mientras que los mayores eran más proclives a mostrar lealtad. Para los autores del estudio se evidenció que los AM tienden a seleccionar con mayor detenimiento las situaciones conflictivas en las que se involucran. 


\subsection{Sobre eventos condicionales}

En muchas ocasiones los argumentos usados contextualmente se manifiestan como actos de habla compuestos. Ejemplos de estos actos de habla compuestos son los actos de habla condicionales. Estas emisiones discursivas se interpretan a través de actos inferenciales. La elección discursiva de esta estructura es estratégica al actuar argumentativamente; sin embargo, la mayoría de las veces las personas usan enunciados condicionales sin saber con certeza el significado de la palabra "condicional". En relación con investigaciones sobre razonamiento en distintos grupos etarios, éstas se han hecho mayoritariamente en condiciones de laboratorio y no con el de lenguaje natural. Por ejemplo, en su investigación, Lacues, Díaz y Huertas (2018) indagaron sobre la efectividad de la enseńanza de las estructuras condicionales en estudiantes de ingeniería, usando como corpus de análisis los textos de clases y los apuntes de los estudiantes después de un semestre de sus cursos de lógica y matemática. Se concluyó que, aunque los sujetos tengan instrucción en lógica, éstos tienden hacia una interpretación bicondicional del contenido causal. Estos resultados afirman la tendencia hacia una evaluación semántica del contenido de las inferencias, y es un desafío, para las facultades de ingeniería, enseñar las formas explícitas de las reglas de inferencia. En este apartado se presenta dos formas de categorizar las estructuras condicionales que, como en el estudio recién citado, están a la base de las investigaciones contemporáneas: una mirada pragmática cognitiva, y una mirada procedimental.

\subsubsection{Mirada pragmática cognitiva}

Una primera forma de categorizar los condicionales no identifica la estructura gramatical, sino que se enfoca en los efectos pragmáticos. Evans y Over (2004) afirman que hay al menos cuatro categorías: indicativos; contrafactuales; deónticos; consejos e incentivos.

En relación con los condicionales indicativos, existe una amplia variedad de usos: por ejemplo, condicionales indicativos que se justifican por una relación causal, "Si gira la llave, el motor arrancará” (Evans y Over 2004: 1). Además, es posible tener condicionales indicativos con una relación temporal, por ejemplo: "Si el primer tren va a Plymouth, entonces el siguiente va a Exeter" (Evans y Over: 1). Evans y Over (2004) afirman que los condicionales causales pueden ser respaldados por leyes científicas, pero a menudo son utilizados por personas comunes para dar consejos. Byrne y Thompson (2002) investigaron el condicional indicativo, "Si Sarah fue a Moose Jaw, entonces Tom fue a Medicine Hat", en oposición al condicional contrafactual, "Si Sarah hubiera ido a Moose Jaw, entonces Tom habría ido a Medicine Hat" (Byrne y Thompson 2002: 1155). Es interesante que el condicional indicativo en Byrne y Thompson (2002) presenta ambas cláusulas en tiempo pasado, Si (tiempo pasado) entonces (tiempo pasado), para relaciones causales. Esta construcción del condicional indicativo ayuda a evaluar y contrastar declaraciones fácticas y contrafácticas, y su posible interpretación (Byrne 2005). Vale la pena mencionar que algunos investigadores han utilizado un condicional indicativo al evaluar el razonamiento 
deductivo (por ejemplo: "Si había un círculo en la pizarra, entonces había un triángulo"), en lugar de contrafactuales (por ejemplo: "Si hubiera habido un círculo en la pizarra, entonces habría habido un triángulo", ambos en Byrne 184).

Los contrafactuales, por su parte, se usan en una declaración condicional siempre y cuando el antecedente y el consecuente no sean verdaderos, sino que sugerencias o presuposiciones pragmáticas como evidencia de una declaración. Un ejemplo es la declaración sobre un estado o una acción que sucedió una vez pero que ya no es posible cambiarla: [Si (pretérito pluscuamperfecto de subjuntivo) entonces (condicional perfecto: habría + participio)], por ejemplo, "Si hubieras evitado la autopista, habrías llegado más rápido" (Evans y Over 2). En este caso, el razonamiento contrafactual es un pensamiento hipotético complejo, pues supone una capacidad estratégica que involucra tanto el pensamiento racional como la imaginación (Byrne 2005). También se puede considerar contrafactual el segundo condicional, por ejemplo: "Si fuéramos como padres, viejitos y ya enfermitos, ahí yo sería a la inversa, ahí yo dejaría que mi hijo se fuera” (Diadas, No. 9, Coquimbo, sujeto 2).

Los indicativos y los contrafácticos se usan para describir la forma en que el mundo pudo haber sido, podría ser o es. Por ejemplo, los eventos naturales y los eventos hipotéticos que pueden ayudar a evitar experiencias pasadas. Sin embargo, los condicionales deónticos se usan para guiar o regular el comportamiento a través del uso de verbos modales como "debe", "debería" y "tener que", por ejemplo, "Si el semáforo está en rojo, entonces debe detenerse" (Evans y Over 3), o en, "Tiene que contarlo...si es que la quiere" (Diadas, No. 12, Concepción, sujeto 1).

Evans y Over (2004) afirman que los condicionales deónticos son un ejemplo de que existe una relación muy estrecha entre la psicología del pensamiento condicional y la psicología de la toma de decisiones. Cuando los sujetos intentan decidir qué hacer, las personas se refieren continuamente a las normas y reglamentos sociales y morales. Esta categoría aún no ha sido explotada en los estudios lingüísticos. Otros ejemplos de esta categoría son: "Si quieres beber alcohol, debes ser mayor de 18 años" (Stenning y van Lambalgen 2004: 493), y "Si una persona es inocente, no debe ser condenado" (Stenning y van Lambalgen 2008: 32). Otro ejemplo condicional deóntico sería el siguiente: "Si el presidente de Chile, Sebastián Piñera, no tiene la capacidad de gobernar, entonces debería renunciar". Esta declaración fue pronunciada en una conferencia de prensa por el presidente del Partido Comunista de Chile el 20 de octubre de 2019, dos días después de las protestas populares masivas en el país.

Otra clase interesante de condicionales, discutida por Couto, Quelhas y Byrne (2017), se utiliza para evaluar la valencia de un resultado. Estas expresiones incluyen consejos (consejos y advertencias) e incentivos (amenazas y promesas), como en los siguientes ejemplos: "Si evitas la autopista, llegarás más rápido" (consejo: el antecedente es la acción apropiada y el consecuente es un resultado deseado); "Si limpias mi automóvil, puedes pedirlo prestado esta noche” (promesa: el antecedente es la acción apropiada y el consecuente es un resultado deseado); "Si fumas cigarrillos, tu salud sufrirâ" (advertencia: 
el antecedente no es la acción apropiada y el consecuente no es un resultado deseado); " $\mathrm{Si}$ llegas tarde otra vez, te despediré" (amenaza: el antecedente no es la acción apropiada y el consecuente no es un resultado deseado) (Evans y Over 4). La mayoría de los ejemplos en esta categoría han sido incluidos en la literatura que analiza la perfección del condicional (PC) (interpretación bicondicional de enunciados condicionales). Un ejemplo de una promesa es: "Si cortas el césped, te daré cinco dólares" (van der Auwera 1997; Byrne 1991; Evans y Over 2004; Geis y Zwicky 1971; Moldovan 2009).

\subsubsection{Mirada procedimental}

Una segunda clasificación es la que proponen Bonnefon y Hilton (2005), quienes han investigado la intención del hablante en situaciones de razonamiento, y afirman que la intención del hablante es argumentativa. Las dos categorías que consideran principales se basan en los principios pragmáticos de las implicaturas y la aceptación ilocutiva, y son: condicionales epistémicos (epistémico básico y precondicionales) y condicionales prácticos (de instrucción y consecuencial). Cuando los argumentos apuntan a la veracidad de una creencia, es posible tener un condicional epistémico, que depende de lo que el hablante conoce. Como resultado, su verdad o falsedad variará. Hay dos subcategorías: "Si es un pájaro, entonces vuela" (Bonnefon y Hilton 2005: 61) es un condicional epistémico básico, que ocurre cuando el consecuente es verdadero, y el antecedente es el caso. La otra subcategoría son las declaraciones precondicionales: " $\mathrm{Si}$ (requisito previo de la conclusión), entonces (conclusión)" (Bonnefon y Hilton: 61). En este contexto, si el requisito previo no es el caso, entonces la conclusión no puede ser el caso. Esta categoría también fue investigada por Byrne (1989), con respecto al efecto de supresión debido a información adicional y alternativa en una inferencia de modus ponens. Por ejemplo, en "Si Mary tiene que escribir un ensayo, entonces estudiará hasta tarde en la biblioteca", el requisito previo es que la biblioteca esté abierta hasta tarde. Si este requisito previo no se cumple, entonces la conclusión podría no ser aceptada. En este caso, el oyente interpretará que las premisas tienen un argumento a favor de la conclusión y un argumento en contra de la conclusión, por lo que es difícil respaldar completamente el modus ponens en este condicional.

Por otro lado, los condicionales prácticos tratan sobre acciones y razonamientos prácticos. En esta categoría, los argumentos apuntan a la idoneidad de la acción, que se incluye como consecuencia o antecedente. La primera subcategoría es la instrucción condicional que tiene la forma "Si (evento) entonces (acción)" (Bonnefon y Hilton: 61). En este caso, la intención del orador es más compleja, ya que el antecedente se transforma en algo necesario para la consecuencia. Un ejemplo es "Si un cliente compra dos maquillajes, ofrécele una muestra de este perfume" (Hilton, Bonnefon y Kemmelmeier 2001: 1). Otra subcategoría de los condicionales prácticos es el condicional consecuencial que tiene la forma "Si (acción) entonces (resultado)" (Bonnefon y Hilton 61). En este caso, el resultado se evalúa en términos de qué tan apropiada es la acción del antecedente. En esta subcategoría, el marco interpretativo argumentativo establece que las personas interpretarán las premisas 
de una tarea de razonamiento condicional como si el objetivo fuera convencer a alguien de la verdad de una creencia o de lo apropiado de una acción. Un ejemplo de perfección del condicional como "Si corta el césped, obtendrá cinco dólares", se puede ajustar también a esta categoría, en el que "cortar el césped" es la acción, y "obtener 5 dólares" es el resultado.

Estas dos categorizaciones dan una idea de la variabilidad de funciones, formas e interpretaciones de la estructura condicional Si $A$, entonces $B$, y a veces las categorías son complementarias y no excluyentes.

\section{Marco MEtodológico}

\subsection{Alcance de la investigación}

El alcance de esta investigación es exploratorio y descriptivo. No se avanzan explicaciones finales sobre la capacidad de producir estructuras condicionales en AM cuando discuten. Nuestro esfuerzo es ofrecer descripciones sistematizadas para compartir ciertas respuestas iniciales que deben ser luego corroboradas o falseadas.

\subsection{Participantes}

Los participantes AM fueron 72 mujeres y 72 hombres, divididos en dos categorías de edad: 65 a 75 años (n 72), y un grupo de 76 años y más (n 72); el promedio de edad es de 74,1 años, con un rango de edad de 65 a 90. Las diadas y triadas se realizaron en tres ciudades distintas: Santiago, Coquimbo y Concepción. Los AM voluntariamente dialogaron sobre un dilema social y no recibieron compensación alguna. No tienen formación en argumentación. Todos los participantes fueron incluidos en el análisis (n 144). Todos los participantes firmaron un consentimiento informado.

\subsection{Materiales}

Los participantes realizaron la tarea en diadas (n 36) y triadas (n 24) bajo su propio control en la interacción. El texto del dilema incluye información que es evaluada como premisa(s) fuerza. Estas premisas forman una matriz de argumentos a favor y en contra de una postura. Para el análisis argumentativo, el dilema y sus premisas pueden ser apoyadas con alternativas a favor de la realización de una posibilidad, o pueden ser rechazadas con contraargumentos en contra de tal realización. Hubo dos dilemas distintos para dos grupos distintos. El primer dilema se llama "El engaño", que se le presentó a 24 diadas (48 sujetos), y el segundo es "El viaje a España", que se le presentó a 12 diadas y a 24 triadas (96 sujetos en total). La tarea de los participantes fue argumentar para expresar una opinión basada en el contenido del dilema. Se les informó a los participantes que el objetivo de este estudio fue examinar cómo las personas argumentan. 
Las variables del grupo son género, edad, educación (solo en diadas) y geografía. Se realizaron 36 diadas: 18 diadas con sujetos entre 65 y 75 ańos y 18 diadas con sujetos mayores de 76 años, organizadas en tres tipos: Hombre-Hombre, Hombre-Mujer y MujerMujer. Los sujetos también fueron clasificados de acuerdo con su nivel educacional en dos categorías: 36 sujetos con educación terciaria (Universitaria) y un grupo de 36 sujetos con educación primaria y secundaria. En el caso de las 24 triadas, 8 triadas se realizaron por ciudad; 12 triadas con sujetos entre 65 y 75 ańos y 12 triadas con sujetos mayores de 76 años. Se combinaron según género en tres tipos de triadas: Hombre-Hombre-Hombre, HombreMujer-Hombre y Mujer-Mujer-Mujer. En las triadas, los sujetos no fueron clasificados de acuerdo con su nivel educacional.

Los dilemas utilizados son los siguientes:

\section{Viaje a España:}

"Pablo es un joven que recién terminó sus estudios de medicina. Por sus buenas notas, su universidad le ofrece una beca para ir a especializarse en Espańa. La oferta es muy buena porque le pagarían un buen sueldo y con una especialidad podría obtener un muy buen empleo después. La beca lo obliga a permanecer en Espańa por cuatro años. Esto lo obligaría a dejar a sus padres, que ya tienen una avanzada edad y serios problemas de salud. Además, están bastante angustiados ante la posible partida de su único hijo. Pablo se encuentra en una verdadera disyuntiva: por un lado, tiene la posibilidad de aprovechar una oportunidad de desarrollo profesional que no siempre se da y, por el otro lado, se enfrenta a una posible separación de sus padres que podría ser definitiva. ¿Cuál cree que sería la mejor decisión de Pablo?”

\section{El engaño:}

"Una pareja lleva tres años casada y está esperando su primer hijo. Durante todo este tiempo, Alicia y Nicolás han sido muy felices y han sido muy sinceros entre ellos. En un cierto momento, se produce una discusión entre ambos, la primera crisis de la pareja, que los deja a los dos resentidos. En ese mismo tiempo, a Nicolás le toca hacer un viaje de negocios y, sin haberlo buscado a propósito, tiene una aventura sexual ocasional. Esto lo hace sentir muy culpable y no sabe qué actitud asumir ante su esposa, teniendo en cuenta que se encuentra embarazada. ¿Debería o no contarle lo sucedido?”

\subsection{Procedimiento}

Se les presentó los dilemas a los participantes y estos dieron su opinión sobre alguno de los dilemas. Las conversaciones se hicieron en un lugar tranquilo en el que no serían interrumpidos, y luego transliteradas para ser analizadas. De las conversaciones entre los AM se extrajeron aquellas ideas y argumentos más comunes; además, se seleccionaron las oraciones condicionales proferidas por los participantes, analizando su frecuencia y contenido. Posteriormente, se clasificó los eventos condicionales a la luz de la taxonomía detallada en 2.2. 


\section{Hallazgos Y ANÁLISIS}

Los participantes argumentaron tomando una posición (apoyar o rechazar). Como resultado, se puede extraer un entramado de argumentos que son el reflejo de la densidad argumentativa de los adultos mayores.

\subsection{Alternativas y Contraargumentos en dilemas sociales}

\subsubsection{Dilema "El viaje a España"}

Los sujetos interactúan en torno a la siguiente problemática: ¿Debería viajar o debería quedarse? La pregunta tiene una estructura disyuntiva que puede ser interpretada de forma exclusiva (similar a "Es lunes o martes, no ambas"), o inclusiva (puede hacer ambas cosas: viajar y ayudar a los padres).

En las siguientes tablas se exponen las premisas fuerza que favorecen o restringen la decisión de viajar. Se extraen las condiciones desde el dilema (lo que explícitamente aparece como información en su redacción) y los contraargumentos y alternativas desde las conversaciones entre los AM.

Tabla 1. Dilema "Viaje a España”. Alternativas para apoyar el viaje

\begin{tabular}{|l|l|}
\hline $\begin{array}{l}\text { Premisas fuerza alternativas para } \\
\text { apoyar el viaje }\end{array}$ & $\begin{array}{l}\text { Posibles contraargumentos para no viajar. Cuestionan las } \\
\text { condiciones a favor }\end{array}$ \\
\hline 1. Hijo exitoso & Puede hacer carrera en Chile y luego viajar. \\
\hline 2. Hijo médico & Puede ayudar a sus padres viejos y enfermos acá primero. \\
\hline 3. Beca paga gastos & Optar por beca en Chile. \\
\hline 4. Buen empleo después & Puede hacer carrera en Chile y luego viajar. \\
\hline
\end{tabular}

Tabla 2. Dilema "Viaje a España". Contraargumentos para rechazar el viaje

\begin{tabular}{|l|l|}
\hline $\begin{array}{l}\text { Premisas fuerza de contraargu- } \\
\text { mentos para rechazar viajar }\end{array}$ & $\begin{array}{l}\text { Posibles alternativas para viajar (contra-contra- argumento). } \\
\text { Cuestionan las condiciones en contra }\end{array}$ \\
\hline 1. Padres viejos y enfermos & $\begin{array}{l}\text { ¿ué tan viejos son? No deben ser tan viejos } \\
\text { Pueden tener distintas edades y ayudarse mutuamente } \\
\text { Puede que uno de los padres solamente esté enfermo } \\
\text { Se puede buscar ayuda para que cuiden a los padres }\end{array}$ \\
\hline 2. Hijo único & La juventud de ahora no tiene apegos, son más libres \\
\hline
\end{tabular}


\begin{tabular}{|l|l}
\hline 3.4 años de beca (mucho tiempo) & Pasará el tiempo volando
\end{tabular} Usar ese dinero para apoyar a los padres en Chile

4. Sin regresar a Chile Puede viajar en sus vacaciones a Chile. Debe tener vacaciones. Ejemplo: diada 3, Coquimbo:

-Sujeto 2: bueno, si va a tener un buen sueldo, un buen pasar allá, que le permita ahorrar y venir una vez al año a ver a sus papás -Sujeto 1: Un muy buen sueldo que permita apoyarlos económicamente

\subsubsection{Dilema "El engaño"}

En este dilema, los sujetos interactúan en torno a la siguiente problemática: ¿Debería él contarle lo sucedido? o ¿No Debería? Similar al dilema anterior, la pregunta tiene una estructura disyuntiva que puede ser interpretada tanto de forma exclusiva como inclusiva. En las siguientes tablas se exponen las premisas fuerza que favorecen o restringen la decisión de contar la infidelidad. Además, se incluyen sus respectivos contraargumentos.

Tabla 3. Dilema "El engaño". Alternativas para apoyar contar la infidelidad

\begin{tabular}{|l|l|}
\hline $\begin{array}{l}\text { Premisas fuerza de alternativas } \\
\text { para apoyar contar }\end{array}$ & $\begin{array}{l}\text { Posibles contraargumentos para no contar. Cuestionan las } \\
\text { condiciones a favor }\end{array}$ \\
\hline Es una pareja feliz & $\begin{array}{l}\text { Puede haber una separación. Perder su matrimonio } \\
\text { Significaría romper la felicidad que han tenido durante tres años } \\
\text { No debería contar para cuidar el amor y el cariño }\end{array}$ \\
\hline Es una pareja sincera & $\begin{array}{l}\text { Hay mucha tentación } \\
\text { Las personas somos débiles } \\
\text { No lo escuchará porque hubo una pelea }\end{array}$ \\
\hline Están esperando su primer hijo & $\begin{array}{l}\text { El niño puede morir antes de nacer } \\
\text { El nińo crecerá sin el padre si se rompe el matrimonio } \\
\text { La madre puede abortar para terminar la relación }\end{array}$ \\
\hline Hay amor y posible perdón & Él no la amaba de verdad \\
\hline El hombre se siente culpable & La infidelidad no fue tan importante \\
\hline
\end{tabular}


Tabla 4. Dilema "El engaño". Contraargumento para rechazar contar la infidelidad

\begin{tabular}{|l|l|}
\hline $\begin{array}{l}\text { Premisas fuerza de contraargu- } \\
\text { mentos para rechazar contar }\end{array}$ & $\begin{array}{l}\text { Posibles alternativas para contar. Cuestionan las condi- } \\
\text { ciones en contra }\end{array}$ \\
\hline Están esperando su primer hijo & El nińo se enterará en el futuro de su infidelidad \\
\hline Hubo una discusión antes & No es razón, él no la amaba de verdad \\
\hline $\begin{array}{l}\text { Hubo engaño pasajero, no es im- } \\
\text { portante. Es ocasional }\end{array}$ & $\begin{array}{l}\text { No se puede vivir el resto de la vida con el engaño } \\
\text { Mejor decir altiro porque después es peor } \\
\text { Nadie es un santo }\end{array}$ \\
\hline $\begin{array}{l}\text { La mujer se enojará. } \\
\text { Evitar un tormento a la esposa }\end{array}$ & La sinceridad es lo más importante en una relación \\
\hline
\end{tabular}

El contenido de estas premisas fuerza contribuye en la construcción de opiniones de los AM. La información extraída desde los dilemas y desde las conversaciones entre los AM es también la base para la producción de enunciados condicionales. Usaremos esta información para identificar si los AM usan este contenido inicial para construir estructuras condicionales.

Los datos relativos a la distribución básica de las respuestas relacionadas con el apoyo o rechazo de las alternativas arrojan los siguientes resultados en función del uso de expresiones condicionales: 1) En el dilema "El engaño", un 68,75\% apoya que el esposo le cuente a su mujer sobre su infidelidad, un 31,25\% rechaza contar la infidelidad. Esto muestra que la mayoría de los AM aprueba tomar una decisión basada en las consecuencias futuras de actos controversiales ("Qué saca con ocultarlo si a la larga e:h, le puede per- e::h perjudicar” (Diadas, No. 2, Santiago, sujeto 1), en un deber moral como la sinceridad y el amor ("si realmente ella lo ama o lo respeta o le quiere dar otra oportunidad es mejor... es mejor que sea sincero y le diga porque a la larga todo esto se va saber" (Diadas, No. 1, Concepción, sujeto 1)), y que el perdón está condicionado a la verdad y el cambio (“¿Ustedes creen que si él- Nicolás le dijera la verdad a- a Alicia ella- ella lo perdonaría?” (Diadas, No. 1, Santiago, sujeto 1)). 2) En el dilema "El viaje a España", un 72,9\% apoya que el hijo viaje a Espańa a hacer la especialización; un 27,08\% rechaza la idea. Esto muestra que la mayoría de los AM aprueba tomar una decisión basada en el ciclo de la vida ("si quiere, si: quiere armarse su futuro, bueno, tiene que hacer ese sacrificio" (Triadas, No. 7, Santiago, sujeto 3)), las oportunidades laborales y educacionales futuras ("Si fuera mi caso yo le diría "hijo" a ojos cerrados, "es tu oportunidad, a veces las oportunidades se dan una sola vez en la vida"” (Triadas, No. 5, Santiago, sujeto 2)), en el deber moral de apoyar al hijo que viaja ("y no piensas tú que los papás si él se queda, los papás van a tener ellos el remordimiento de decir "por culpa nuestra, nuestro hijo va a trabajar de mozo por ahí"” (Triadas, No. 8, Santiago, sujeto 1), y que el viaje está condicionado a que los padres estén bien cuidados ("Ahora si el hijo busca a alguien con quien dejar a esos padres amparados, porque pensemos que el hijo 
es solo, me entendí. Entonces, pero si él busca el apoyo y deja a los padres bien ubicados, entonces él se va a ir tranquilo" (Triadas, No. 2, Santiago, sujeto 3)).

\subsubsection{Secuencias tipicas de argumentos usados en diadas y triadas}

En la siguiente figura se ejemplifica esquemáticamente los recorridos argumentativos de las unidades mínimas en la secuencia argumentativa hallada en las conversaciones. Ya que ambos dilemas han sido presentados a través de una toma de decisión disyuntiva, se presenta una disyunción también en la secuencia.

Figura 1. Diagrama de interacciones argumentativas en diadas y triadas.
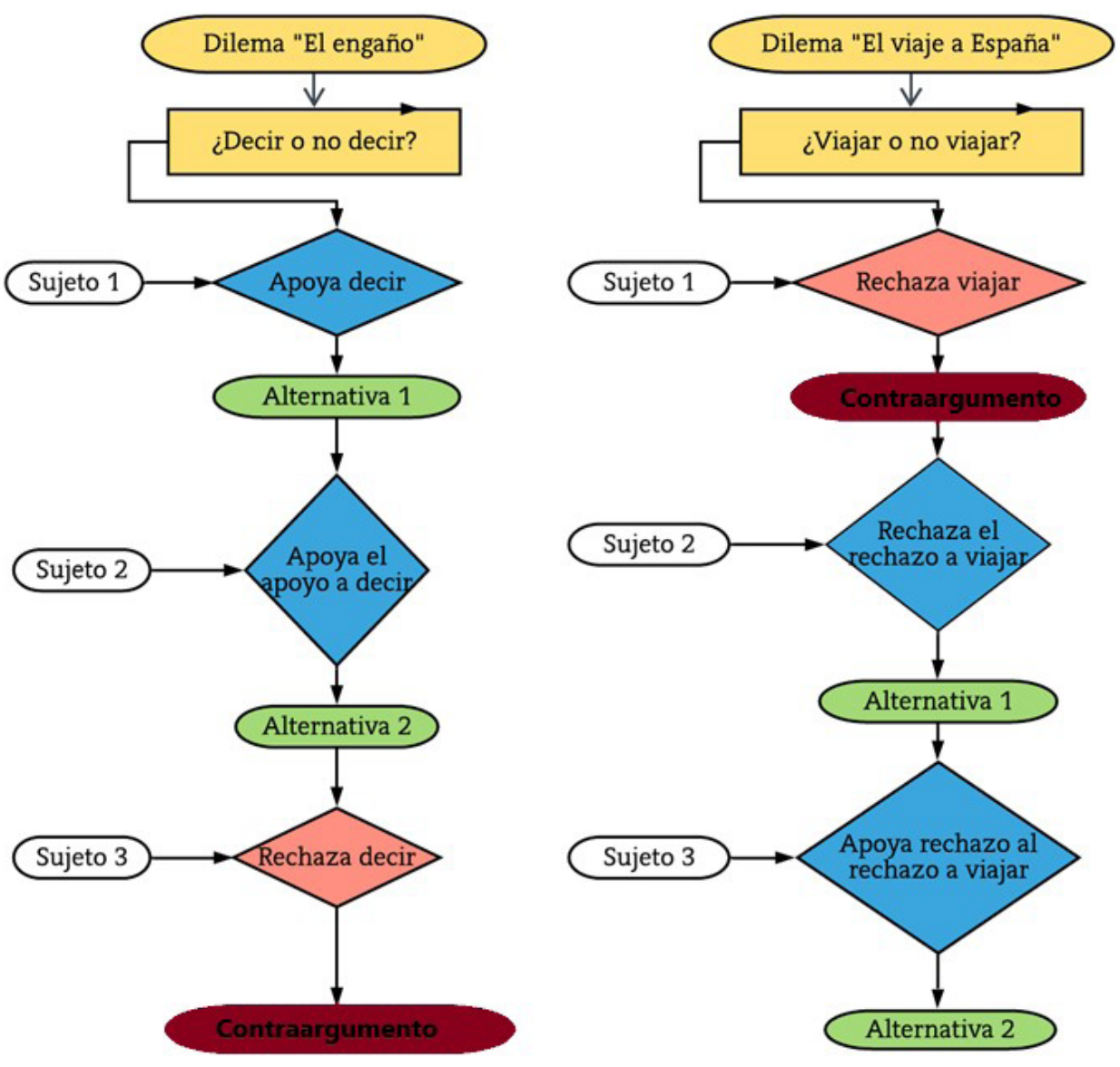
Al escuchar, por ejemplo, las premisas del dilema "El Engaño", los sujetos toman la postura, mayoritaria en nuestra muestra, de apoyo a contar el engaño ańadiendo alternativas en la argumentación. El siguiente interlocutor podía apoyar, aceptando la o las alternativas, o podía añadir nuevas alternativas. También podía rechazar añadiendo contraargumentos, dependiendo del caso. Así, el siguiente interlocutor podía tanto apoyar o rechazar alternativas, o podía rechazar o apoyar contraargumentos. Estas secuencias son dinámicas haciéndose en algunos casos muy largas y de forma compuesta. Los enunciados condicionales se encuentran incrustados en estas secuencias, y sirven de apoyo argumentativo para justificar puntos de vista.

\subsection{Usos de condicionales}

Nos interesa particularmente identificar interpretaciones bicondicionales como una tendencia en los adultos mayores. La tendencia a la interpretación bicondicional sobre estructuras condicionales (Si A entonces $B$ ) validan los cuatro silogismos lógicos condicionales: Modus Ponens (MP), Modus Tollens (MT), Negación del Antecedente (NA), y Afirmación del Consecuente (AC). Por ejemplo, "Si es un buen hijo, va a ir en beneficio de los papás" (Diadas, No. 11, Coquimbo, sujeto 1). Este condicional se puede reescribir como: "Si es un buen hijo, ayudará a sus padres enfermos". Estas son las formas deductivas válidas:

a. MP: 1. Si es buen hijo, entonces ayudará a sus padres

2. Es un buen hijo

3. Entonces, ayudará a sus padres

b. MT: 1. Si es buen hijo, entonces ayudará a sus padres

2. No ayudará a sus padres

3. Entonces, no es un buen hijo

c. NA: 1. Si es buen hijo, entonces ayudará a sus padres

2. No es un buen hijo

3. Entonces, no ayudará a sus padres

d. AC: 1. Si es buen hijo, entonces ayudará a sus padres

2. Ayudará a sus padres

3. Entonces, es un buen hijo

Si todas las formas anteriores son aceptadas, entonces estamos en presencia de una interpretación bicondicional. Los dos modelos aceptados son:

1. Buen hijo ayuda

2. No buen hijo no ayuda

No es necesario que los sujetos sean explícitos en enunciar un bicondicional de la forma "Si y sólo si es un buen hijo, ayudará a sus padres", basta con la expresión condicional 
para aceptar MP ("Porque si es un hijo bueno y se preocupa, y ha visto que sus padres le han dado todo en la vida, yo creo que sería una preocupación grande” (Triadas, No. 1, Santiago, sujeto 3)) y MT ("sino que, si me voy =puede que no los veo más, entonces e:: me parece bastante egoísta del Pablo" (Triadas, No. 2, Coquimbo, sujeto 2). Además, el contexto pragmático y la evaluación del contenido ayuda a interpretar que si ayuda es necesario ser buen hijo (AC), por ejemplo, "pero si puede llevar a sus papás y pasar bien con sus medios en otra parte, está bien" (Triadas, No. 6, Coquimbo, sujeto 2), y que si no es buen hijo no ayudará a los padres (NA), como en "pero si es un mal hijo a lo mejor se va y los deja solos" (Triadas, No. 6, Santiago, sujeto 1).

En los condicionales, la creación de alternativas o contraargumentos a las premisas incluye conocimiento previo o creencias. No necesariamente se siguen las restricciones del condicional material, el cual sólo acepta MP y MT, sino que se puede aceptar AC y NA. Por ejemplo, Blanchette (2006), y Blanchette y El-Deredy (2014) han investigado el razonamiento con contenido emocional, y concluyen que el efecto de la emoción en los enunciados condicionales no seguiría los componentes lógicos del razonamiento. Lo que pasaría es que, en enunciados como " $\mathrm{Si}$ alguien está en una situación trágica, entonces llorará” (Blanchette 2006: 1113), tiende a tener una aceptación de AC y NA más alta, por lo tanto, éstos serán probablemente interpretados como bicondicionales. Como resultado, la razón y la toma de decisión son procesos cognitivos complejos que dependerán de distintos elementos no lógicos.

\subsubsection{Resultado de las frecuencias de eventos condicionales}

Se realizó un análisis estadístico con la plataforma JAMOVI (The jamovi project (2019); versión 1.1; consultado en: https://www.jamovi.org). Al analizar la cantidad de eventos condicionales (n 287) realizados por los sujetos de todas las conversaciones (n 144 ), se puede observar los siguientes resultados relativos a variables como edad (65 a 75 vs 76 y más años), género (mujeres vs hombres), y geografía (Santiago vs Coquimbo vs Concepción). En el análisis de varianza ANOVA, con variable dependiente (número de eventos) x variables participantes (edad, género, y geografía) no se encontró diferencias significativas en las variables independientes de edad $\left(F(1,132)=2.454, p=.120, \eta^{2} \mathrm{p}=.018\right)$, y género $\left(\mathrm{F}(1,132)=0.883, \mathrm{p}=.3459 \mathrm{y}^{2} \mathrm{p}=.007\right)$. No se encontró una interacción significativa entre las tres variables independientes $\left(\mathrm{p}_{\mathrm{s}}>\right.$.116). Sin embargo, sí se encontró una diferencia significativa en la variable geografía $\left(\mathrm{F}(2,132)=29.456, \mathrm{p}<.001, \mathrm{y}^{2} \mathrm{p}=.309\right)$. 
Figura 2. Medias estimadas de las variables edad, género y geografía.

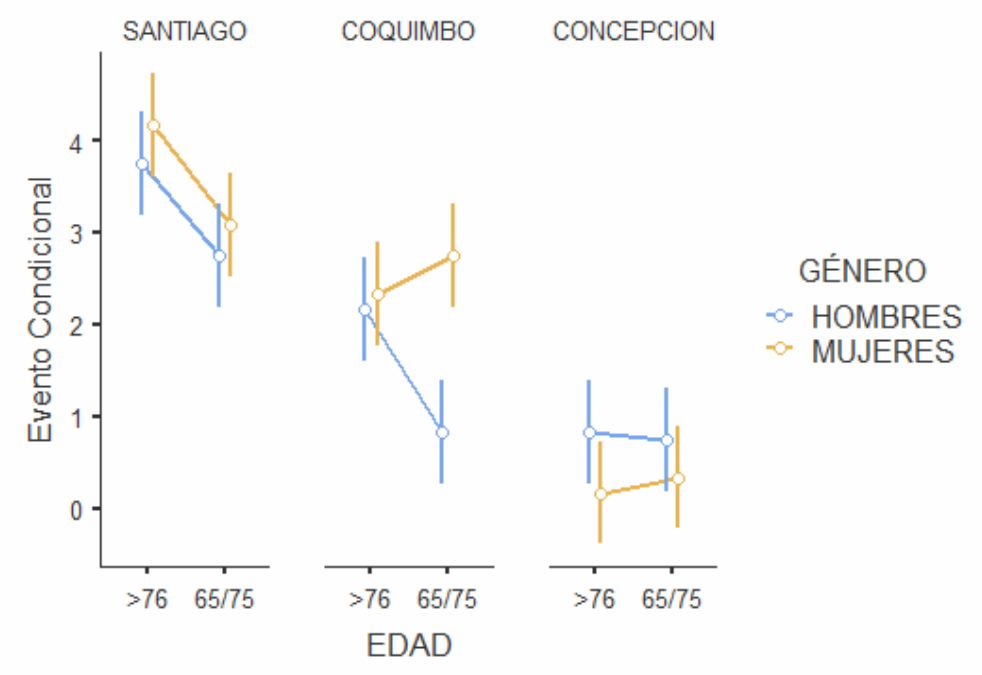

En el siguiente histograma se refleja la homogeneidad del grupo estudiado y la frecuencia de enunciados condicionales relativas a edad, género y geografía, incluyendo el tipo de conversación (diadas y triadas).

Figura 3. Histograma con frecuencias relativas a edad, género y grupo.

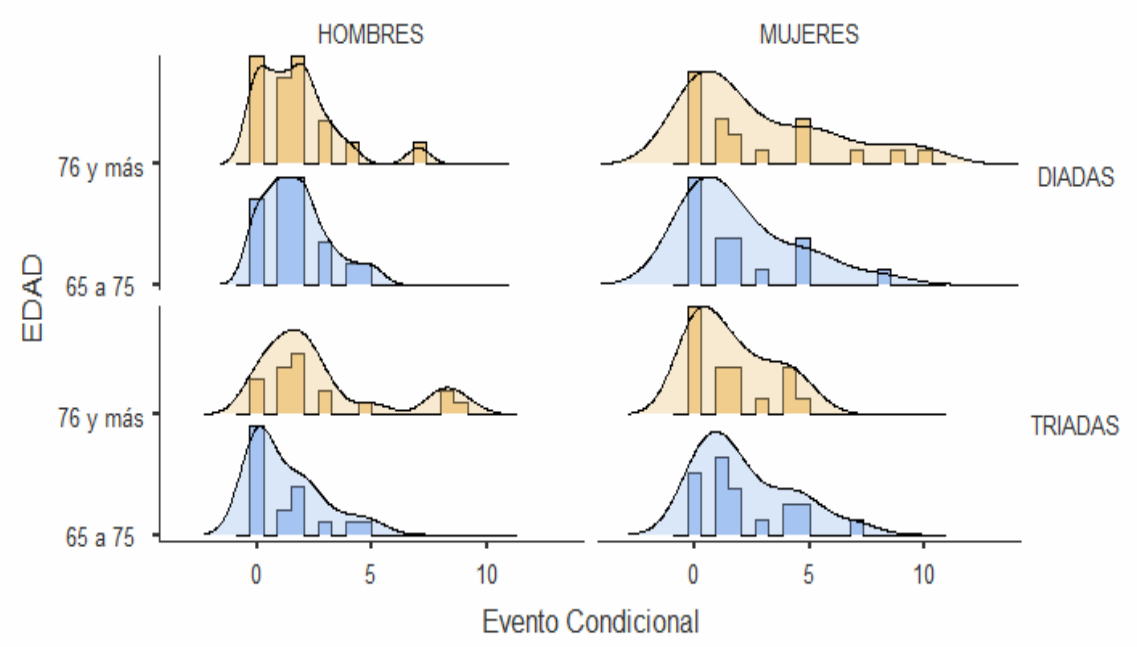


En relación con la diferencia significativa de la variable geografía ( $\mathrm{p}<.001)$, una posible limitación del estudio puede ser la diferencia en la longitud de las conversaciones entre los AM al comparar las tres áreas geográficas. Las conversaciones realizadas en Santiago tienen una extensión mayor que las conversaciones de Coquimbo y mucho mayor que las de Concepción. Esto puede explicar los promedios de cada ciudad.

Figura 4. Porcentajes estimados en las variables fijas edad, género, grupo y geografía.
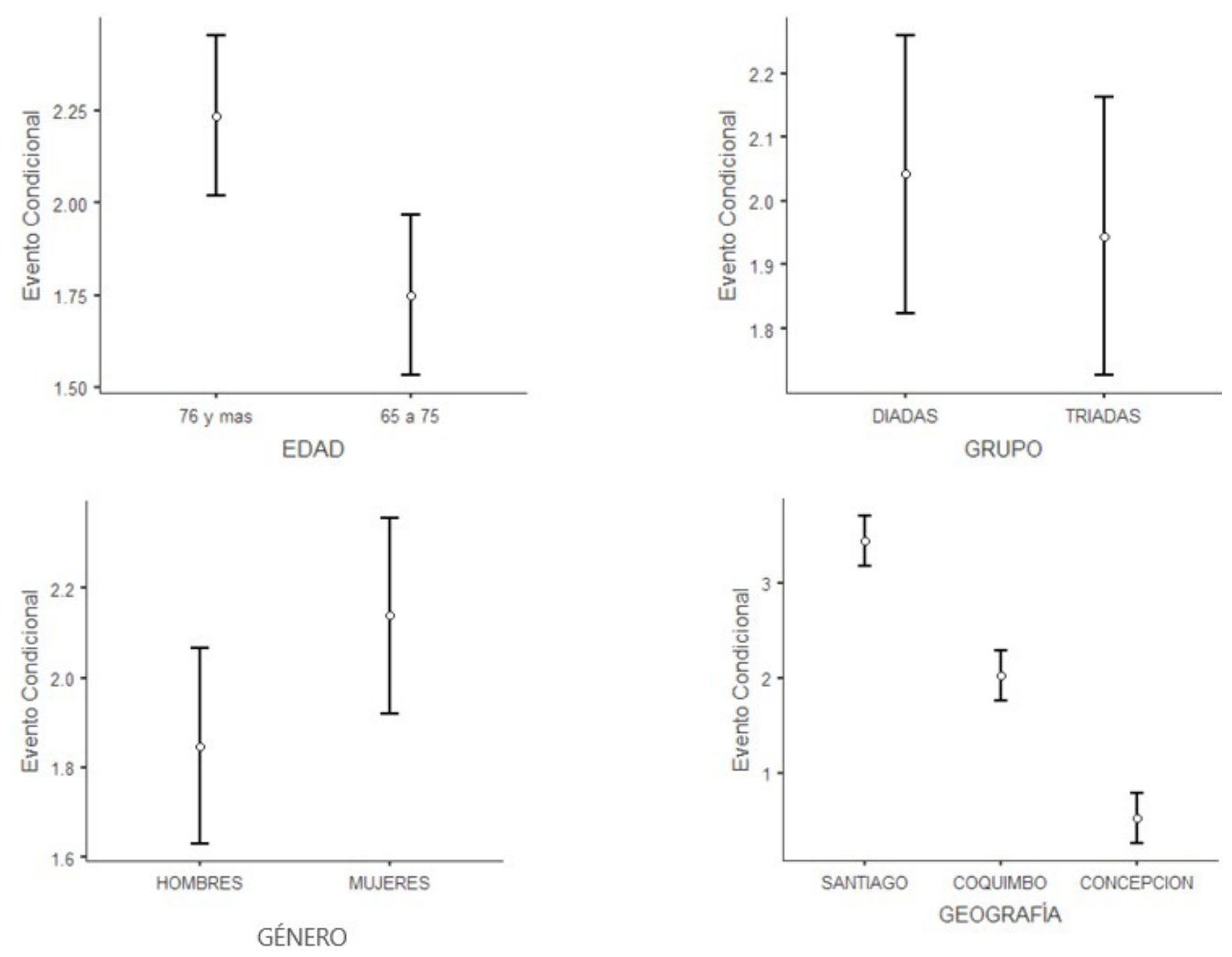

Las diadas (n 72) incorporaron la variable educación (Educación Media vs Universitaria). El análisis de varianza ANOVA con variable independiente (número de condicionales) $\mathrm{x}$ variables participantes (edad, género y educación) no arrojó diferencias significativas en educación $\left(\mathrm{F}(1,64)=2.177, \mathrm{p}=.145, \mathrm{y}^{2} \mathrm{p}=.033\right)$. Tampoco arrojó diferencias significativas entre las distintas interacciones de las variables. El siguiente gráfico muestra la interacción entre las variables género, edad y nivel educacional. 
Figura 5. Porcentajes estimados marginales de la interacción edad, género y educación.

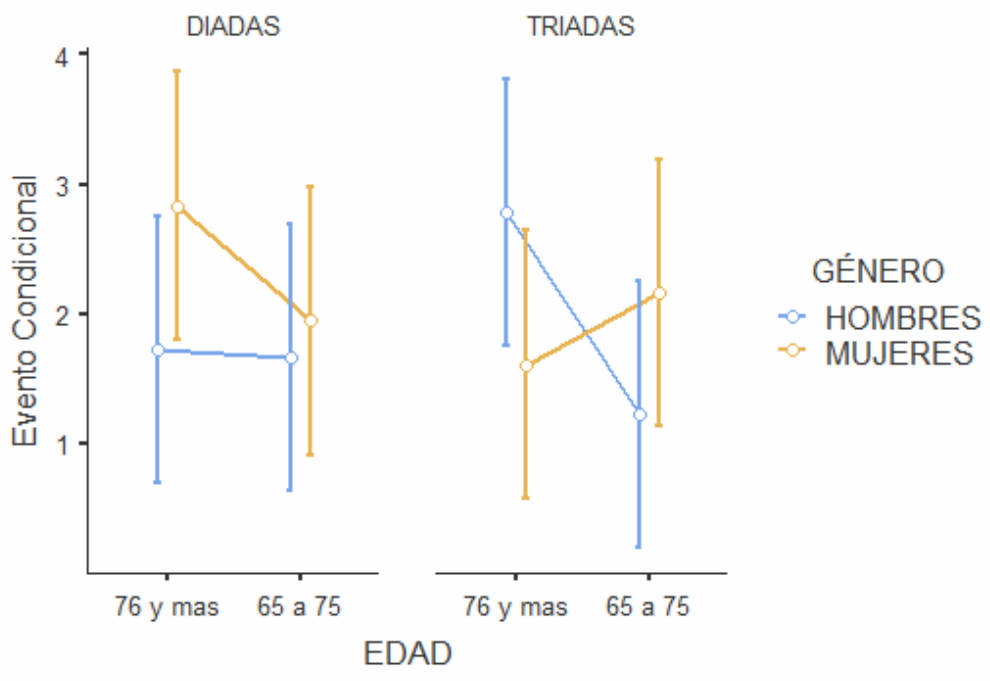

$\mathrm{Al}$ evaluar a las diadas y las triadas por separado, no se encontraron diferencias significativas dentro de cada una, excepto por la variable geografía en ambos tipos de conversación $(\mathrm{p}<.001)$. Sabiendo que no hay diferencias significativas entre los sujetos, sus mayores diferencias se expresan de la siguiente manera. Por un lado, en las diadas se encontró una mayor diferencia entre las mujeres universitarias mayores de 76 ańos de Santiago que utilizaron más estructuras condicionales que las mujeres universitarias mayores de 76 años de Concepción (PostHoc pbonferroni=.029). Por otro lado, en las triadas se encontró una mayor diferencia entre los hombres mayores de 76 ańos de Santiago que emitieron más enunciados condicionales que los hombres entre 65 y 75 ańos de Concepción (PostHoc pbonferroni=.031).

\subsubsection{Evaluación de taxonomía condicional y ejemplos con premisas fuerza}

Se realizó un análisis de los eventos condicionales a través de la combinación de la taxonomía expuesta en el apartado 2.2. De acuerdo con estas dos clasificaciones, se puede evidenciar que comparten teóricamente algunas similitudes expresadas en la siguiente figura: 
Figura 6. Similitudes de las taxonomías sobre estructuras condicionales.

\begin{tabular}{|ccc|}
\hline \multicolumn{3}{|c|}{ Taxonomía de eventos condicionales } \\
\hline Capel \& Sharp (2003) & Evans \& Over (2004) & Bonnefon \& Hilton (2005) \\
\hline $0^{\circ}$ condicional & & Indicativo \\
$1^{\circ}$ condicional & Epistém ico (básico y precondicional) \\
\hline $2^{\circ}$ condicional & Contrafactual & $\mathrm{x}$ \\
$3^{\circ}$ condicional & Deóntico & Práctico de instrucción (evento - acción) \\
\hline $\mathrm{x}$ & Consejos e incentivos $\longrightarrow$ Práctico consecuencial (acción - resultado) \\
\hline
\end{tabular}

Se puede observar que una gran cantidad de condicionales son consejos, que por lo general se interpretan como bicondicionales. El contenido de los enunciados condicionales encontrados no es neutral ni abstracto, más bien es un contenido conectado con las premisas fuerza de los dilemas. También se puede observar que un 15\% de los condicionales emitidos son condicionales contrafactuales, de los cuales la mayoría son segundos condicionales. El resto de los condicionales son indicativos y deónticos. Los condicionales deónticos se caracterizaron por ser condicionales prácticos que dan instrucciones en un esquema "eventoacción”.

Se ha realizado una revisión de los enunciados condicionales y se ha encontrado que, junto con diversos temas relacionados con el contenido de los dilemas, las premisas fuerza han sido clave para construir representaciones mentales que ayudan a argumentar y posiblemente a tomar una decisión. Algunos ejemplos obtenidos de las respuestas de los AM de estructuras condicionales relacionadas con contenido clave de los dilemas se entrega a continuación con un etiquetado de acuerdo con las clasificaciones discutidas en el apartado 2.2 .

\subsection{Estructuras condicionales en las conversaciones dilemáticas entre AM}

En la siguiente tabla ofrecemos algunos ejemplos, para el caso de El viaje a España, que demuestran los tipos de usos de estructuras condicionales que los AM compartieron con sus pares durante los diálogos dilemáticos, en que se destaca la premisa fuerza, la forma del condicional utilizado, y la taxonomía a la que pertenece: 
Tabla 5. Estructuras condicionales en El viaje a España

\begin{tabular}{|c|c|c|c|c|}
\hline Expresión de AM & $\begin{array}{l}\text { Premisa } \\
\text { fuerza }\end{array}$ & $\begin{array}{l}\text { Sintaxis del } \\
\text { condicional }\end{array}$ & $\begin{array}{l}\text { Taxonomía } 1 \\
\text { (Evans y Over 2004) }\end{array}$ & $\begin{array}{l}\text { Taxonomía } 2 \\
\text { (Bonnefon y Hilton 2005) }\end{array}$ \\
\hline $\begin{array}{l}\text { "si tienen buen cere- } \\
\text { bro para estudiar, que } \\
\text { las aprovechen altiro } \\
\text { para su futuro que } \\
\text { viene si po" (Triadas, } \\
\text { No. 3, Santiago, suje- } \\
\text { to 2) }\end{array}$ & Hijo exitoso & $\begin{array}{l}\text { Presente + } \\
\text { presente }\end{array}$ & Indicativo & $\begin{array}{l}\text { Práctico-instrucción } \\
\text { (evento-acción) }\end{array}$ \\
\hline $\begin{array}{l}\text { "yo creo que si Pablo } \\
\text { se va a España sería } \\
\text { un mejor profesio- } \\
\text { nal" (Triadas, No. 4, } \\
\text { Santiago, sujeto 3) }\end{array}$ & Hijo exitoso & $\begin{array}{l}\text { Presente }+ \\
\text { condicional }\end{array}$ & Indicativo & $\begin{array}{l}\text { Práctico-consecuencial } \\
\text { (acción-resultado) }\end{array}$ \\
\hline $\begin{array}{l}\text { "Si es médico enton- } \\
\text { ces ya puede ejercer, } \\
\text { ganar experiencia, es- } \\
\text { perar a que sus padres } \\
\text { se mueran" (Triadas, } \\
\text { No. 2, Coquimbo, } \\
\text { sujeto 2) }\end{array}$ & Hijo médico & $\begin{array}{l}\text { Presente + } \\
\text { presente }\end{array}$ & Indicativo & $\begin{array}{l}\text { Epistémico precondi- } \\
\text { cional }\end{array}$ \\
\hline $\begin{array}{l}\text { "si va becado, el tipo } \\
\text { de BECA no va a re- } \\
\text { querir ayuda de sus } \\
\text { papás" (Diadas, No. } 2 \text {, } \\
\text { Coquimbo, sujeto 2) }\end{array}$ & $\begin{array}{l}\text { Beca paga } \\
\text { gastos }\end{array}$ & $\begin{array}{l}\text { Presente + } \\
\text { futuro; } \\
\text { indicativo; } \\
\text { epistémico } \\
\text { precondicional } \\
\end{array}$ & Indicativo & $\begin{array}{l}\text { Epistémico precondi- } \\
\text { cional }\end{array}$ \\
\hline $\begin{array}{l}\text { "si es una buena } \\
\text { BECA, es otro país, } \\
\text { otra realidad, Chile } \\
\text { ya lo conoce, =es que } \\
\text { yo creo que igual= yo } \\
\text { me iría" (Triadas, No. } \\
\text { 7, Coquimbo, sujeto } \\
\text { 1) }\end{array}$ & $\begin{array}{l}\text { Beca paga } \\
\text { gastos }\end{array}$ & $\begin{array}{l}\text { Presente + } \\
\text { presente }\end{array}$ & Deóntico & $\begin{array}{l}\text { Epistémico precondicio- } \\
\text { nal }\end{array}$ \\
\hline $\begin{array}{l}\text { "si va a tener un buen } \\
\text { sueldo, un buen pa- } \\
\text { sar allá, que le permi- } \\
\text { ta ahorrar y venir una } \\
\text { vez al año a ver a sus } \\
\text { papás" (Diadas, No. } \\
\text { 2, Coquimbo, sujeto } \\
\text { 2) }\end{array}$ & $\begin{array}{l}\text { Buen } \\
\text { empleo } \\
\text { después }\end{array}$ & $\begin{array}{l}\text { Presente + } \\
\text { presente }\end{array}$ & Indicativo & $\begin{array}{l}\text { Epistémico precondicio- } \\
\text { nal }\end{array}$ \\
\hline
\end{tabular}




\begin{tabular}{|c|c|c|c|c|}
\hline $\begin{array}{l}\text { "si él se fuera para } \\
\text { allá, él tendría un fu- } \\
\text { turo para su próxima } \\
\text { familia" (Triadas, No. } \\
\text { 2, Santiago, sujeto 2) }\end{array}$ & $\begin{array}{l}\text { Buen } \\
\text { empleo } \\
\text { después }\end{array}$ & $\begin{array}{l}\text { Subjuntivo + } \\
\text { condicional }\end{array}$ & Contrafactual & $\begin{array}{l}\text { Práctico consecuencial } \\
\text { (acción-resultado) }\end{array}$ \\
\hline $\begin{array}{l}\text { "Si fuéramos como } \\
\text { padres, viejitos y ya } \\
\text { enfermitos, ahí yo } \\
\text { sería a la inversa, ahí } \\
\text { yo dejaría que mi } \\
\text { hijo se fuera" (Dia- } \\
\text { das, No. 9, Coquim- } \\
\text { bo, sujeto 2) }\end{array}$ & $\begin{array}{l}\text { Padres vie- } \\
\text { jos y enfer- } \\
\text { mos }\end{array}$ & $\begin{array}{l}\text { Subjuntivo } \\
\text { - pretérito } \\
\text { pluscuam- } \\
\text { perfecto + } \\
\text { condicional }\end{array}$ & Contrafactual & $\begin{array}{l}\text { Epistémico precondicio- } \\
\text { nal }\end{array}$ \\
\hline $\begin{array}{l}\text { "si son mayores y es- } \\
\text { tán enfermos, pienso } \\
\text { yo que: su compro- } \\
\text { miso debería de ser } \\
\text { con los papás" (Dia- } \\
\text { das, No. 10, Co- } \\
\text { quimbo, sujeto 2) }\end{array}$ & $\begin{array}{l}\text { Padres vie- } \\
\text { jos y enfer- } \\
\text { mos }\end{array}$ & $\begin{array}{l}\text { Presente }+ \\
\text { condicional }\end{array}$ & $\begin{array}{l}\text { Deóntico (debe- } \\
\text { ría) }\end{array}$ & $\begin{array}{l}\text { Epistémico precondicio- } \\
\text { nal }\end{array}$ \\
\hline $\begin{array}{l}\text { "si los papás tienen } \\
\text { serios problemas de } \\
\text { salud, si Dios se lo } \\
\text { quiere llevar, se los } \\
\text { van a llevar igual po' } \\
\text { hijo" (Triadas, No. } 5 \text {, } \\
\text { Santiago, sujeto 3) }\end{array}$ & $\begin{array}{l}\text { Padres vie- } \\
\text { jos y enfer- } \\
\text { mos }\end{array}$ & $\begin{array}{l}\text { Presente + } \\
\text { futuro }\end{array}$ & Indicativo & $\begin{array}{l}\text { Epistémico precondicio- } \\
\text { nal }\end{array}$ \\
\hline $\begin{array}{l}\text { "Yo igual, buscaría } \\
\text { aquí más cerca. En } \\
\text { alguna parte donde } \\
\text { estudiar porque estar } \\
\text { cerca de mis padres. } \\
\text { Si es su único hijo" } \\
\text { (Triadas, No. 3, San- } \\
\text { tiago, sujeto 3) }\end{array}$ & Hijo único & $\begin{array}{l}\text { Presente }+ \\
\text { condicional }\end{array}$ & Indicativo & $\begin{array}{l}\text { Práctico instrucción } \\
\text { (evento-acción) }\end{array}$ \\
\hline
\end{tabular}

Las expresiones de los AM muestran una construcción de representaciones mentales a partir de la información de los dilemas. Éstas luego son recuperadas al momento de argumentar a favor o en contra. Al comparar las taxonomías 1 y 2, se evidenció que la categoría deóntica se manifestó junto con la categoría práctica de instrucción, y no con la categoría práctica consecuencial. Esto muestra que los condicionales deónticos y condicionales práctico-instructivo tienden a complementarse, tanto en su sintaxis como en su sentido pragmático (lo que se observa en la Tabla 5). Podemos señalar que los 
condicionales deónticos son práctico-instructivos, pero no al revés, ya que expresiones instructivas pueden ser llevada a cabo también por condicionales contrafactuales, "Si me tocara a mí, yo optaría por quedarme" (Diadas, No. 9, Coquimbo, sujeto 2), o indicativos, "si él ya tiene un trabajo, es cosa de pedir permiso" (Diadas, No. 9, Coquimbo, sujeto 1).

Los sujetos en este estudio han mostrado un dominio amplio de distintas manifestaciones condicionales tanto en su sintaxis como en su uso pragmático. Este amplio dominio comunicativo ayuda a la construcción hipotética de realidades posibles por medio de premisas fuerza extraídas de los dilemas y su conocimiento y/o experiencias previas.

\section{DisCuSión Y CONCLUSIONES}

A pesar de la importancia del pensamiento condicional e hipotético, su estudio en AM no se ha llevado a cabo con la profundidad que se desearía. Como ya hemos indicado, el crecimiento sistemático de la población adulta mayor en el mundo plantea el desafío de estudiar varias de las dimensiones de la cognición de personas sobre 65 años, y una de ellas es el uso de estructuras condicionales en el discurso, particularmente en contextos argumentativos.

Una primera observación es indicar que en la muestra de discursos de AM que hemos analizado se encuentra ejemplos de enunciados condicionales que calzan con las dos taxonomías del (uso) de expresiones condicionales discutidas en este estudio, a saber: A) la perspectiva semántico-pragmática vinculada a los estudios cognitivos (Evans y Over 2004), y B) la perspectiva que enfatiza el rol de la fuerza argumentativa y procedimental (Bonnefon y Hilton 2005).

Entre los hallazgos destaca que una gran cantidad de condicionales son consejos, que otro porcentaje importante de los condicionales emitidos fueron condicionales contrafactuales y deónticos, caracterizándose estos últimos como condicionales prácticos que dan instrucciones en un esquema evento-acción. Los hallazgos más importantes, no obstante, son que las premisas fuerza tienen un rol clave en los enunciados condicionales de los adultos mayores, y que la variable que genera una diferencia cuando se comparan las diadas y triadas es ubicación geográfica (esto es, más o menos urbanidad), y no así educación, género o tramo etario específico dentro de la adultez mayor.

Respecto de los primeros hallazgos (una gran cantidad de condicionales son consejos, y otro grupo importante de expresiones son condicionales contrafactuales y deónticos) no solo, y obviamente, están en relación con la experiencia acumulada de quien emite la opinión, sino que también están en línea con otros hallazgos (Santibáñez 2019) relativos a tendencias instrumentales de adoptar posiciones que enfatizan beneficios futuros en vez de posiciones que enfatizan castigo. Como se indicó en el análisis, en el dilema "El engaño" un 68,75\% apoya que el esposo le cuente a su mujer sobre su infidelidad para evitar problemas futuros. Esto último queda de manifiesto en opiniones en condicional como: "Qué saca con ocultarlo si a la larga e:h, le puede per- e::h perjudicar" (Diadas, No. 2, 
Santiago, sujeto 1), o en la siguiente opinión en que se combina lo pragmático con un deber moral: "Si realmente ella lo ama o lo respeta o le quiere dar otra oportunidad es mejor... es mejor que sea sincero y le diga porque a la larga todo esto se va saber" (Diadas, No. 1, Concepción, sujeto 1). Algo similar ocurrió con el dilema "El viaje a España", ya que un $72,9 \%$ apoyó que el hijo viaje a España a hacer la especialización profesional, que queda de manifiesto en: "Si quiere, si: quiere armarse su futuro, bueno, tiene que hacer ese sacrificio" (Triadas, No. 7, Santiago, sujeto 3), o en: "Si fuera mi caso yo le diría "hijo" a ojos cerrados, "es tu oportunidad, a veces las oportunidades se dan una sola vez en la vida"” (Triadas, No. 5, Santiago, sujeto 2).

En relación con los dos hallazgos principales de la investigación, a saber, que las premisas fuerza tienen un rol clave en los enunciados condicionales de los adultos mayores, y que la variable que genera una diferencia es ubicación geográfica, se puede indicar lo siguiente.

Se observó que gran parte de las premisas fuerza utilizadas provenían de la información contenida en los dilemas mismos, lo que puede ser interpretado como una estrategia inteligente por parte de los AM de economizar energía cognitiva en el uso de memoria operativa y búsqueda en la memoria enciclopédica de razones y/o argumentos novedosos. Pero este anclaje discursivo de utilizar la información de los dilemas también puede verse como un tipo de dependencia argumentativa. Sin embargo, esta última línea interpretativa es menos sólida, ya que los tipos de conclusiones (apoyar o no apoyar contar infidelidad o viaje a España) no estaban sugeridas, por lo que es razonable advertir que se trata de una estrategia discursiva inteligente para respaldar opiniones motivadas por la situación específica.

En relación con el peso más significativo de la variable ubicación geográfica (que se traduce en el contexto chileno de mayor o menor urbanidad), este dato converge con otros hallazgos en torno al discurso argumentativo en AM. Se pudo observar en otro estudio (Santibáńez y Gascón 2020) que la calidad argumentativa (medida por los criterios de relevancia, aceptabilidad y suficiencia de las razones para apoyar una conclusión) de los AM estaba en relación con el lugar de residencia, siendo el caso que a mayor urbanidad del lugar de residencia mayor calidad argumentativa. Aun no se puede determinar con exactitud qué variable dentro de un espacio de mayor urbanidad, influye más decididamente en la calidad del discurso argumentativo de los hablantes, pero es sensato suponer que las personas tenemos mayor contacto social en tales contextos lo que generaría la necesidad de intercambiar más opiniones constantemente.

La importancia del lugar de residencia también está vinculada con la expresión de enunciados condicionales en un tramado argumentativo, ya que se observó, a través de un análisis PostHoc, que mujeres sobre 76 años en Santiago utilizaron más estructuras condicionales que sus pares de Concepción (la segunda ciudad en Chile en términos de tamańo e importancia económica). Si desde el punto de vista teórico el uso de estructuras lingüísticas condicionales es expresión de pensamiento hipotético y contrafactual, que es a su vez uno de los niveles superiores de capacidad cognitiva (Evans 2007) ya que 
permite generar el cotejo de alternativas para tomar cursos de acción o generar contextos supuestos de consecuencias de nuestras decisiones, entonces es interesante también notar que comparadas entre sí muestras similares en relación con la variable género (en este caso mujer), un desempeño más robusto frente a una tarea discursiva que la exigía (reflexionar sobre una situación dilemática) está determinado también por la variable geográfica o, quizás, con la cantidad de intercambios de opinión que supondría vivir en contextos urbanos más desarrollados.

\section{OBRAS CITADAS}

Birditt, Kira \& Karen Fingerman. 2005. "Do we get better at picking our battles? Age group differences in descriptions of behavioral reactions to interpersonal tensions". Journal of Gerontology 60.3: 121-128.

Blanchette, Isabelle. 2006. "The effect of emotion on interpretation and logic in a conditional reasoning task". Memory and Cognition 34.5: 1112-1125.

Blanchette, Isabelle \& Wael El-Deredy. 2014. "An ERP investigation of conditional reasoning with emotional and neutral contents". Brain and Cognition 91: 45-53.

Bonnefon, Jean-Francois \& Denis Hilton. 2005. "Getting to the Point of Conditionals: An Argumentative approach to the psychological interpretation of Conditional Premises". En Gabriele Kern-Isberner, Friedhelm Kulmann y Wilhelm Dder (eds.), Conditionals, Information, and Inference. Berlin: Springer. 59-64.

Bonnefond, Mathilde \& Jean-Baptiste Van der Henst. 2013. "Deduction electrified: ERPs elicited by the processing of words in conditional arguments". Brain \& Language 124: 244-256.

Byrne, Ruth \& Valerie Thompson. 2002. "Reasoning Counterfactually: Making Inferences about Things That Didn't Happen. Journal of experimental psychology”. Learning, memory, and cognition 28.6: 1154-1170.

Byrne, Ruth. 1989. "Suppressing valid inferences with conditionals". Cognition 31: 61-83. . 2005. The Rational Imagination: how people create alternatives to reality. Cambridge, Mass.: MIT Press.

. 1991. "Can valid inferences be suppressed?". Cognition 39: 71-78.

Couto, Marta, Ana Quelhas \& Ruth Byrne. 2017. "Advice conditionals about tips and warnings: interpretations and inferences". Journal of Cognitive Psychology 29.3: 364380 .

Evans, Jonathan. 2007. Hypothetical Thinking: Dual Processes in Reasoning and Judgement. Hove: Psychology Press.

. 2010. Thinking Twice. Two Minds in One Brain. New York: Oxford University Press.

Evans, Jonathan y David Over. 2004. If. New York: Oxford University Press.

Geis, Michael \& Arnold Zwicky. 1971. "On invited inferences”. Linguistic Inquiry 2: 561566. 
Hilton, Denis, Jena-Francois Bonnefon \& Markus Kemmelmeier. 2001. "Pragmatics at Work: Formulation and Interpretation of Conditional Instructions". En Johanna Moore y Keith Stenning (eds.), Proceedings of the 23rd Annual Conference of the Cognitive Science Society. Hillsdale: Lawrence Erlbaum. 417-422.

Instituto Nacional de Estadísticas. 2018. Características sociodemográficas de la inmigración internacional en Chile Censo 2017. https://www.ine.cl/docs/defaultsource/demogr\%c3\%a 1 ficas-yvitales/inmigraci $\%$ c3\%b3n/s\%c3\%adntesis. pdf?sfvrsn=795659d2_4

Lacues, Eduardo, Leonora Díaz \& Juan Huertas. 2018. “¿Qué Estructuras Deductivas Usan Alumnos Ingresantes a la Universidad?” Bolema: Boletim de Educação Matemática 32.62: 802-824.

Lange, Paul van, Bettina Rockenbach \& Toshio Yamagishi. 2014. Reward and Punishment in Social Dilemmas. New York: Oxford University Press.

Lawson, Anton. 2004. "Reasoning and Brain Function". En Jacqueline Leighton y Robert Sternberg (eds.), The nature of Reasoning. New York: Cambridge University Press. $12-48$.

Luo, Minxia, Megan Robbins, Mike Martin \& Burcu Demiray. 2019. "Real-Life Language Use Across Different Interlocutors: A Naturalistic Observation Study of Adults Varying in Age". Front. Psychol., 25 June 2019 | https://doi.org/10.3389/ fpsyg.2019.01412

Moldovan, Andrei. 2009. "Pragmatic Considerations in the Interpretation of Denying the Antecedent". Informal Logic 29.3: 309-326.

Santibáńez, Cristián. 2019. "Generosos y empáticos o ¿pragmáticos y utilitaristas?: Los argumentos del adulto mayor chileno frente a un dilema social". Lingüistica $y$ Literatura 75: 174-208.

Santibáńez, Cristián \& Gascón, José. 2020. “¿Quién argumenta mejor? Esquemas y calidad argumentativa en adultos mayores y jóvenes chilenos". Círculo de lingüística aplicada a la comunicación 81: 249-278.

Schullery, Nancy \& Stephen Schullery. 2003. "Relationship of argumentativeness to age and higher education". Western Journal of Communication 67.2: 207-223.

Soto, Christopher, Oliver John, Samuel Gosling \& Jeff Potter. 2011. "Age differences in personality traits from 10 to 65: Big Five domains and facets in a large cross-sectional sample”. J Pers Soc Psychol. 100.2: 330-348.

Stenning, Keith \& Michiel van Lambalgen. 2004. "A little logic goes a long way: Basing experiment on semantic theory in the cognitive science of conditional reasoning". Cognitive Science 28.4: 481-530. .2008. Human reasoning and Cognitive science. Cambridge, Mass.: The MIT press.

van der Auwera, Johan. 1997. "Pragmatics in the last quarter century: the case of conditional perfection”. Journal of Pragmatics 27: 261-274. 
